\title{
REVISÃO E RECOMENDAÇÕES PARA O CALCULO E CLASSIFICAÇÃO DE RESERVAS MINERAIS
}

\author{
JORGE KAZUO YAMAMOTO* \& MARCELO MONTEIRO DA ROCHA**
}

\begin{abstract}
REVIEW AND RECOMMENDATIONS FOR CCMMPUTING AND CLASSIFYING MINERAL RESERVES This paper presents a review of ore reserve classification schemes adopted in Brazil, as well as recommendations for computing and classifying ore reserves. Ore reserve classification scheme aims at sorting computed reserves in classes according to the corresponding confidence levels. The mineral reserve is a part of geological resource that can be mined with profit at the time of its determination. The degree of confidence is a function of natural variability of mineral deposits, as measured by the coefficient of variation. However, it is important to observe that for deposits presenting high variability, exploration does not furnish sufficient information for classes of higher confidence.

According to modern trends, reserves are estimated from resource models. Resources are classified in decreasing order of confidence as measured, indicated or inferred. Estimated reserves from resources, after considering economical, mining, metallurgical, marketing, legal, environmental, social and political factors, are classified in proved and probable, in decreasing order of confidence, which are derived from measured and indicated resources, respectively. In 1990, the National Department of Mineral Production (DNPM, Brazil) created a work group which has proposed alteration in the Mining Code and Correlated Legislation based on a new model for classification of resources/reserves. This model is up-to-date and adopted worldwide, but the work group also proposed alternative definitions for resources and reserves, which are here considered inadequate for the reasons presented in this paper. Ore reserve estimation follows a logical sequence of steps: geological evaluations, exploration method and sampling evaluations, exploration data evaluation, ore body delineation and selection of an appropriate method for ore reserve estimation. Following these steps, the ore reserve classification of an ore block becomes a natural consequence of the relative density of samples.
\end{abstract}

Key words: ore reserve classification, ore reserve estimation, mineral reserves, mineral resources.

RESUMO Este trabalho apresenta uma revisão das classificações de reservas adotadas no Brasil, bem como recomendacões para o cálculo e classificação de reservas. A classificacão de reservas tem por objetivo agrupar as reservas calculadas em classes, de acordo com o grau de certeza associado às mesmas. De acordo com a terminologia corrente, a reserva mineral é uma parte do recurso geológico, que pode ser lavrada com lucro ao tempo de sua determinação. $\mathrm{O}$ grau de certeza associado à reserva depende da variabilidade natural dos depósitos minerais, medida pelo coeficiente de variação. Contudo, é importante ressaltar que para depósitos com alta variabilidade natural, os trabalhos de pesquisa não permitem detalhar as reservas para classes de maior confiança.

De acordo com a tendência atual, as reservas são estimadas a partir de modelos de recursos. Os recursos são classificados, em ordem decrescente de certeza, em medido, indicado ou inferido. As reservas estimadas a partir dos recursos, após consideração de fatores econômicos, de mineração, metalúrgicos, mercadológicos, legais, ambientais, sociais e políticos, são classificadas em provada e provável, as quais são derivadas de recursos medido e indicado, respectivamente.

Em 1990, o Departamento Nacional da Produção Mineral constituiu um grupo de trabalho que propôs a alteração do Código de Mineração e Legislação Correlativa, com base em novo modelo de classificação de recursos/reservas. Trata-se de um modelo atualizado e aceito internacionalmente, porém o grupo de trabalho propôs algumas definições alternativas para recursos e reservas, as quais foram consideradas inadequadas, conforme os motivos apresentados neste trabalho.

O cálculo de reservas segue uma sequiência lógica constituída pelos seguintes passos: avaliações geológicas, avaliações do método de pesquisa e amostragem, delineação do corpo mineral e seleção de um método apropriado para o cálculo de reservas. Seguindo esses passos, a classificação de reservas de um bloco de cubagem, dá-se como conseqüência natural da densidade relativa de amostras.

Palavras-chaves: classificação de reservas, cálculo de reservas, reservas minerais, recursos minerais.

INTRODUÇÃO A quantificação de reservas minerais, em termos de teores e tonelagens, deve ser acompanhada de uma medida do grau de confiabilidade associado às mesmas. Este grau de confiabilidade é inerente aos métodos de pesquisa utilizados, métodos analíticos, precisão da localização dos pontos de amostragem e, sobretudo, à variabilidade apresentada pelo corpo de minério. Há que se ressaltar que materiais geológicos podem apresentar variações na geometria do corpo de minério, nas características físicas do minério e, conseqüentemente, na distribuição de teores no mesmo, como resultado da interação dos processos geológicos responsáveis pela sua gênese. As classificações de reservas permitem expressar quantidades de minério, de acordo com o grau de precisão e conhecimento associado às mesmas.

Assim, as classificações de reservas são fundamentais para comunicação de reservas minerais, que podem ser convertidas em valores monetários e daí serem objeto de investimento, negociação e de indenização. Todos os estudos de viabilidade técnica e econômica de um empreendimento de mineração fazem uso do quadro de reservas minerais do depósito.

Este trabalho apresenta uma revisão crítica das classificações de reservas no Brasil, apresentando a terminologia envolvida e a modificação desses esquemas como resultado da evolução dos conceitos e métodos de cálculos de reservas, bem como recomendações para o cálculo/classificação de reservas.

\section{CLASSIFICAÇÃO DE RESERVAS: CONCEITOS}

Segundo Froidevaux (1982), pela classificação de reservas o geólogo tenta responder uma questão fundamental: qual o grau de certeza de que há metal realmente e em que quantidade?

* Departamento de Geologia Econômica e Geofísica Aplicada, Instituto de Geociências, Universidade de São Paulo. Caixa Postal 11.348, CEP 05.422-970, São Paulo, Brasil. E-mail: jkyamamo@usp.br.

** Aluno do Programa de Pós-Graduação em Recursos Minerais e Hidrogeologia, Instituto de Geociências, Universidade de São Paulo. Caixa Postal 11.348, CEP 05.422-970, São Paulo, Brasil. E-mail: mmrocha@usp.br. 
A expressão reserva mineral implica que algum tipo de medição física tenha sido feita do teor e da quantidade de concentração mineral in situ e, além disso, que a sua extração seja viável do ponto de vista tecnológico, hoje ou num futuro próximo, e que possa ser realizada com lucro (Zwartendyk 1972 apud Machado 1989). Nesta definição de reserva mineral tem-se a primeira alteração da terminologia corrente, uma vez que as reservas devem ser econômica e tecnologicamente viáveis no momento atual, caso contrário deverão ser mantidas como recursos geológicos.

É importante diferenciar recurso geológico de reserva mineral que, segundo Noble (1993), corresponde a uma pequena fração do primeiro (1/5 a 1/3), de acordo com o estágio da pesquisa mineral. A Figura 1, apresenta uma típica progressão de recursos geológicos para reservas minerais (Noble 1993).

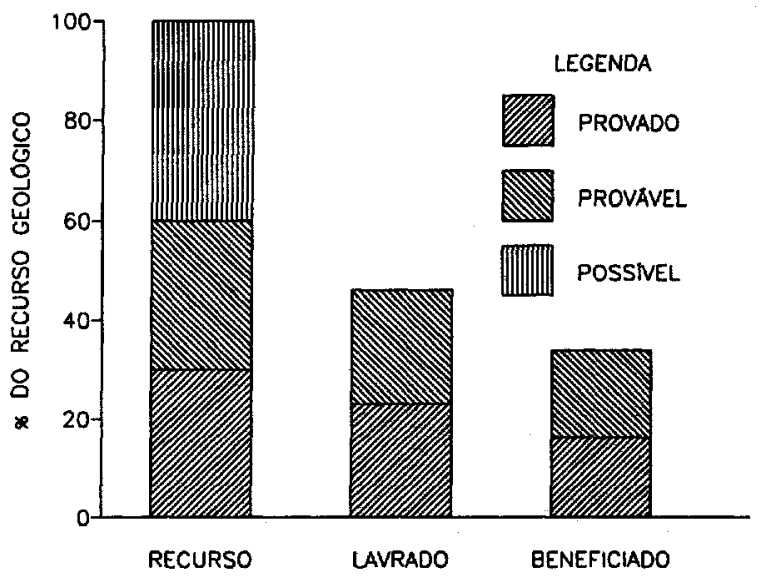

Figura 1 - Progressão típica de recursos geológicos para reservas minerais, segundo Noble (1993).

Figure 1 - Typical progression from geological resources to mineral reserves, after Noble (1993)

A Figura 2 ilustra o procedimento técnico para a determinação da reserva mineral lavrável, a partir de estudos técnicoeconômicos visando o aproveitamento do recurso geológico in situ. Parte do recurso geológico, como mostrado nesta figura, permanecerá in situ, pois não apresentou viabilidade no momento da determinação da reserva mineral lavrável.

Segundo Noble (1993), o erro mais comum na avaliação de reservas minerais se dá pela inclusão de "minério possível" na estimativa. Ainda segundo o mesmo autor, existem duas boas razões para exclusão do material possível das estimativas de reservas:

- recursos possíveis não podem ser incluídos em reservas minerais de acordo com as regras da U.S. Securities and Exchange Commission;

- estimativas de recursos possíveis tendem a superestimar a quantidade de minério que será definitivamente provado. Como mostrado na Figura 3, a estimativa de recurso para um típico corpo de minério aumenta com a sondagem adicional, à medida que os contatos do corpo de minério são conhecidos, até os limites laterais serem definidos. Quando os limites laterais do recurso estão determinados, as sondagens no interior do corpo delineiam o corpo e definem a continuidade da mineralização. Durante o período de delineação, o recurso estimado geralmente declina para depois estabilizar-se num nível constante.
A)

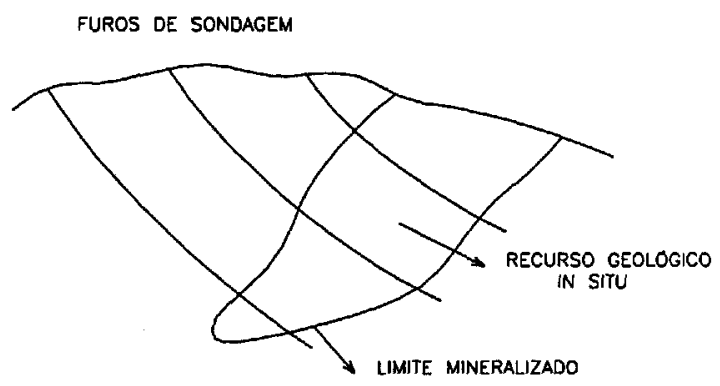

B)

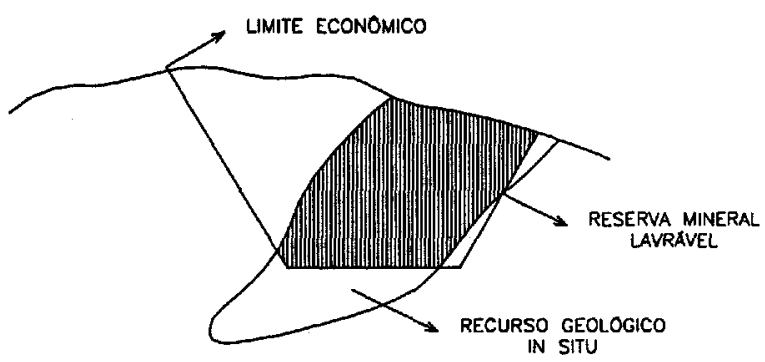

Figura 2 - Determinação do recurso geológico in situ $(A) e$ da reserva mineral lavrável (B).

Figure 2 - Determination of in situ geological resource (A) and mineable mineral reserve (B).

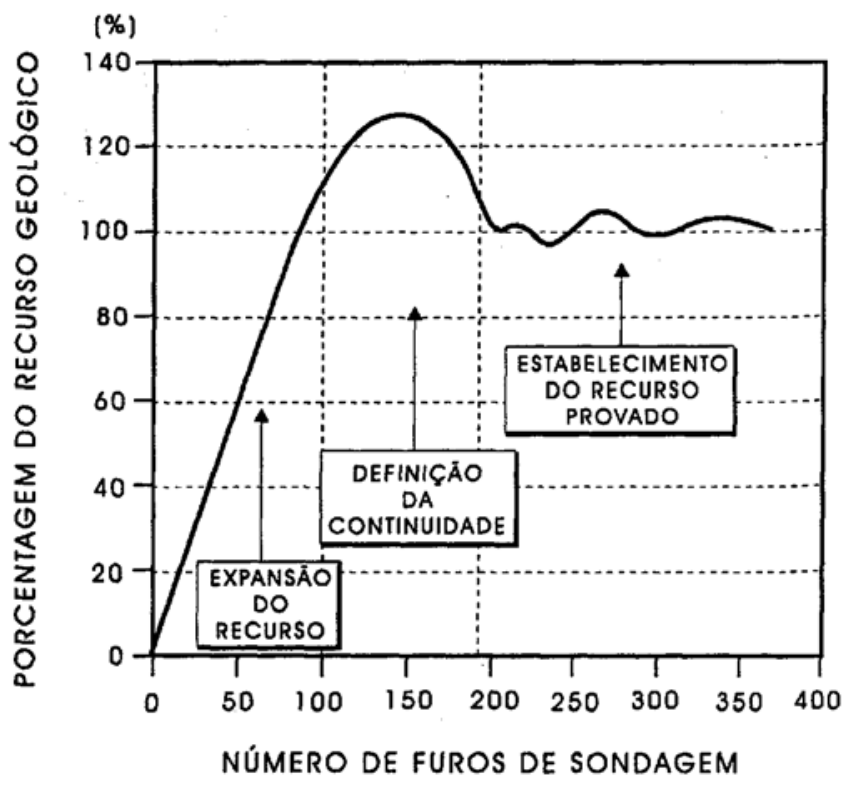

Figura 3 - Evolução dos recursos geológicos em função do número de furos de sondagem para um típico corpo de minério, segundo Noble (1993).

Figure 3 - Evolution of geological resources as a function of number of drill holes for a typical ore body, according to Noble (1993) 
As principais classificações de reservas adotadas no mundo, estão baseadas fundamentalmente na confiança geológica e viabilidade econômica. Tais classificações usam o grau de certeza de reservas como fator discriminante entre as várias classes, entretanto, nenhum desses esquemas mostra claramente como se calcula o erro associado a uma dada estimativa. Como conseqüência da dificuldade em quantificar o erro de estimativa, o geólogo irá utilizar uma área de influência subjetiva (distância) em torno dos furos de sondagem como um critério para discriminação entre reservas provada e provável (Froidevaux 1982).

Os recursos podem ser subdivididos em dois grupos: econômico e subeconômico. Reservas são parte dos recursos econômicos que podem ser lavrados e processados com lucro, enquanto os recursos subeconômicos não podem ser lavrados com lucro sob as condições econômicas atuais. •

Os recursos podem ser considerados subeconômicos por várias razões (Diatchkov 1994):

- recursos pequenos ou insuficientes;

- espessura insuficiente do corpo de minério;

- baixos teores do minério;

- altas concentrações de componentes estéreis;

- alto custo de processamento; e

- ambiente geográfico desfavorável.

Segundo Jeffreys (1987), a indústria mineral reconhece que é necessário levarem consideração não somente os fatores teor e recuperação na usina, mas também igualmente os custos de lavra e beneficiamento, assim como o preço corrente de mercado para o bem mineral. Assim, ainda de acordo com aquele autor, a reserva econômica recuperável de um dado recurso irá variar no tempo, assim como o custo e o preço variam em resposta à atualização tecnológica e aos fatores econômicos.

"Reserva é a quantidade de uma dada subștância, apta a ser lavrada, em função de estudos econômicos. É prática corrente incluir na reserva o material que tem qualificação química, mineralógica e física e que pode ser lavrável por boa técnica, mas que não produz lucro, agora. Mudados alguns condicionantes, passa a fazer parte da base de reservas. $\mathrm{O}$ conceito de recurso é, pois conseqüência do conceito de reserva", in Grossi Sad \& Valente (1996). Embora os conceitos de recursos e reservas estejam consolidados nas classificações mais recentes, Grossi Sad \& Valente (1996), em recente revisão sobre o assunto, fazem confusão entre os termos reserva e recurso, como reproduzido neste parágrafo.

\section{CLASSIFICAÇÃO DE RESERVAS E VARIABILI-} DADE NATURAL DOS DEPÓSITOS MINERAIS

Qualquer modelo de classificação de reservas deve levar em consideração a variabilidade natural do depósito mineral, expressa pelo coeficiente de variação. Esta medida de dispersão estatística dos dados tem sido utilizada pela escola soviética de exploração mineral, inclusive para fins de classificação de depósitos minerais (Grossi Sad 1986).

O coeficiente de variação é dado pela razão entre o desvio padrão e a média da população amostrada, conforme segue:

$$
C V=\frac{S}{\bar{X}}
$$

onde:

$X$ é a média da variável de interesse no depósito e $\mathrm{S}$ é o desvio padrão da média.

O coeficiente de variação reflete a dispersão geral da variável de interesse no depósito (teor, espessura, densidade, etc.). A dispersão calculada pelo desvio padrão poderá refletir a assimetria da distribuição de freqüências (distribuições lognormais), bem como o grau de achatamento da distribuição de freqüências (distribuições normais) e/ou a combinação desses dois parâmetros estatísticos. A Figura 4 mostra os coeficientes de variação para algumas distribuições com assimetrias e graus de achatamento diferentes.

Assim, o coeficiente de variação pode ser utilizado para classificar os depósitos minerais em termos geológicos e geométricos. Nesse sentido, uma classificação dos depósitos minerais, baseada na estrutura geológica e complexidade da mineralização, bem como na forma do corpo de minério, foi proposta por Diatchkov (1994) com o objetivo de limitar o trabalho de prospecção necessário para o detalhamento das reservas, visando classes de certeza maior.

A classificação de Diatchkov (1994), reconhece 4 grupos baseados na estrutura geológica e complexidade de mineralização:

I: compreende depósitos minerais, que são caracterizados por estruturas geológicas simples, nos quais as reservas são concentradas em depósitos não disseminados, com espessura uniforme e no qual o teor do minério é contínuo através do depósito;

II: compreende depósitos minerais caracterizados por estruturas geológicas complexas, espessuras irregulares, distribuição irregular de teores ou que tenham sido afetados por falhas;

III: inclui depósitos minerais com estruturas geológicas altamente complexas e variações significativas de espessura, marcados por uma distribuição muito irregular do minério, ou por uma mineralização que tenha sido deslocada por falhas;

IV: cobre aqueles depósitos minerais que exibem estruturas geológicas extremamente complexas, variações drásticas na

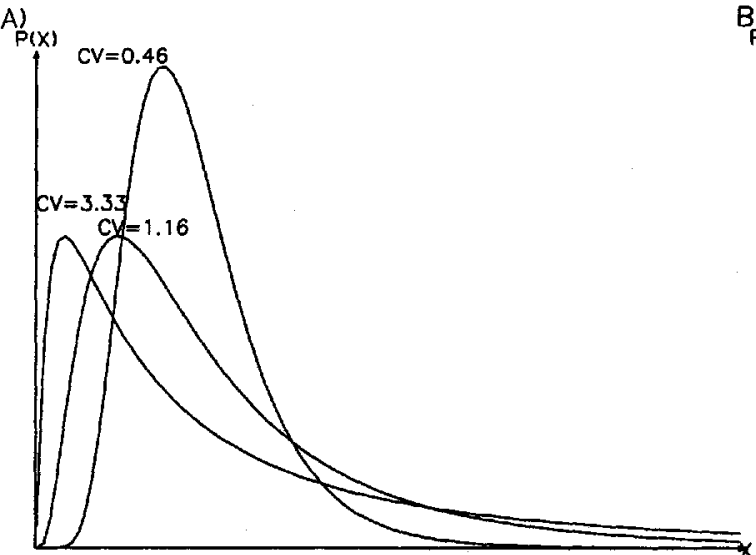

$B(x)$



Figura 4 - Coeficientes de variação para distribuições com diferentes graus de assimetria em distribuições lognormais (A) e com diferentes graus de achatamento em distribuições normais (B).

Figure 4 - Coefficients of variation for distributions with different skewnesses in lognormal distributions (A) and different kurtoses in normal distributions (B). 
espessura, distribuição mineral extremamente irregular, ou que ocorrem em depósitos disseminados afetados por intenso falhamento;

e 5 grupos baseados na forma do corpo de minério:

1: Depósitos acamadados médios e grandes (carvão, ferro, metais base, urânio, terras-raras, rochas ornamentais, etc.). $\mathrm{O}$ método de pesquisa típico é a sondagem;

2: Stockworks, corpos eqüidimensionais e grandes depósitos maciços (carvão, ferro, metais base e preciosos, rochas ornamentais e não metálicos). $\mathrm{O}$ método de pesquisa para esses tipos de depósitos inclui normalmente geologia de superfície em combinação com sondagem ou outros tipos de perfis verticais em aberturas subterrâneas existentes;

3: Veios e lentes em depósitos pequenos ou médios (ferro, metais base, metais preciosos e terras-raras, urânio). À pesquisa combina geologia de superfície e sondagem, escavações subterrâneas e levantamento de seções verticais e horizontais;

4: Chaminés e veios anastomosados em depósitos pequenos ou médios (ferro, metais base e preciosos, pedras preciosas). A pesquisa desse grupo de depósitos requer sondagem e trabalhos subterrâneos com sondagens direcionais;

5: Lentes pequenas e isoladas, veios e bolsões (metais preciosos, terras raras e pedras preciosas). A pesquisa desses depósitos é conduzida através de uma rede de trabalhos subterrâneos.

"Os especialistas em pesquisa mineral não devem se sentir acanhados por causa da linguagem um tanto esotérica aplicada por alguns geológicos (sic) na descrição dos depósitos minerais. Em geral pode ser afirmado que nenhuma importância tem, para o estudo das reservas minerais, se o depósito foi gerado em um margem continental ativa ou em uma posição pós-arco ou pré-arco insular, etc", in Grossi Sad \& Valente (1996). Os parâmetros geológicos (estrutura geológica e complexidade da mineralização) e geométricos (dimensões e forma do corpo), observados em um depósito mineral, resultam da interação dos fenômenos geológicos responsáveis pela sua gênese. Assim, o conhecimento do ambiente geológico e, conseqüentemente, do modelo conceituai do depósito são fundamentais para orientar os trabalhos de pesquisa mineral e avaliação de reservas.

Observe-se que os critérios: estrutura geológica e complexidade da mineralização e forma do corpo, podem ser combinados dando origem a uma matriz bidimensional, que pode ser utilizada agora para classificação dos depósitos minerais segundo a variabilidade na espessura e teor, medidas pelo coeficiente de variação (Tabelas 1 e 2). A Tabela 3 mostra a correspondência entre as categorias de reservas de Diatchkov (1994) e as classes de reservas, segundo a AIMM (1996).

Tabela 1 - Distribuição do coeficiente de variação (\%) da espessura para diferentes grupos de depósitos minerais (Diatchkov 1994).

Table 1 - Distribution of the coefficient of variation (\%) of thickness in different mineral deposits (Diatchkov 1994).

\begin{tabular}{|c|c|c|c|c|}
\hline \multirow{2}{*}{$\begin{array}{c}\text { Grupos baseados na } \\
\text { forma do } \\
\text { corpo mineral }\end{array}$} & \multicolumn{4}{|c|}{$\begin{array}{c}\text { Grupos baseados na estrutura geológica e na } \\
\text { complexidade da mineralização }\end{array}$} \\
\cline { 2 - 5 } & I & II & III & IV \\
\hline $\mathbf{1}$ & $5-20$ & $20-50$ & $50-70$ & - \\
\hline 2 & $15-30$ & $30-60$ & $60-80$ & - \\
\hline 3 & - & $40-80$ & $80-120$ & - \\
\hline 4 & - & $50-70$ & $60-100$ & - \\
\hline 5 & - & - & - & $100-150$ \\
\hline $\begin{array}{c}\text { Categoria de } \\
\text { Reservas }\end{array}$ & $\mathrm{A}+\mathrm{B}$ & $\mathrm{B}$ & $\mathrm{C}_{1}$ & $\mathrm{C}_{2}$ \\
\hline
\end{tabular}

Tabela 2 - Distribuição do coeficiente de variação (\%) do teor para diferentes grupos de depósitos minerais (Diatchkov 1994).

Table 2 - Distribution of the coefficient of variation of grade for different groups of mineral deposits (Diatchkov 1994).

\begin{tabular}{|c|c|c|c|c|}
\hline $\begin{array}{c}\text { Grupos baseados } \\
\text { na forma do } \\
\text { corpo mineral }\end{array}$ & \multicolumn{4}{|c|}{$\begin{array}{c}\text { Grupos baseados na estrutura geológica e na } \\
\text { complexidade da mineralização }\end{array}$} \\
\cline { 2 - 5 } & I & II & III & IV \\
\hline $\mathbf{1}$ & $10-30$ & $40-70$ & $100-120$ & - \\
\hline $\mathbf{2}$ & $10-50$ & $40-60$ & $100-150$ & - \\
\hline $\mathbf{3}$ & - & $50-100$ & $150-200$ & - \\
\hline $\mathbf{4}$ & - & $50-80$ & $200-300$ & - \\
\hline $\mathbf{5}$ & - & - & - & $>300$ \\
\hline $\begin{array}{c}\text { Categorias de } \\
\text { Reservas }\end{array}$ & $\mathrm{A}+\mathrm{B}$ & $\mathrm{B}$ & $\mathrm{C}_{1}$ & $\mathrm{C}_{2}$ \\
\hline
\end{tabular}

Tabela 3 - Correlação entre a terminologia de Diatchkov (1994) e AIMM (1996).

Table 3 - Correlation between Diatchkov's (1994) and AIMM's (1996) terminology.

\begin{tabular}{|c|c|}
\hline $\begin{array}{c}\text { Categorias de reservas } \\
\text { (Diatchkov 1994) }\end{array}$ & $\begin{array}{c}\text { Classes de reservas } \\
\text { (AIMM 1996) }\end{array}$ \\
\hline A+B & provada \\
\hline C1 & provável \\
\hline C2 & - \\
\hline
\end{tabular}

A classificação de Diatchkov (1994) é extremamente prática pois, mostra claramente que, para depósitos com alta variabilidade natural, os trabalhos de pesquisa não permitem detalhar as reservas para classes de maior confiança geológica, devido aos altos custos envolvidos.

ESTIMATIVA DE RESERVAS A PARTIR DE MODELOS DE RECURSOS De acordo com a tendência atual, reservas são parte dos recursos geológicos, as quais são viáveis tecnológica e economicamente no momento da sua determinação. Portanto, fica implícito que as reservas pertencem à categoria de reservas lavráveis.

Assim, o modelo corrente para a estimativa de reservas a partir de recursos segue aquele proposto pela indústria australiana de mineração, conforme reproduzido na Figura 5, segundo AIMM (1996).

A terminologia adotada pelo Código Australiano para Comunicação de Recursos Minerais Identificados e Reservas Minerais (AIMM 1996) encontra-se no Anexo I.

Os recursos são classificados, de acordo com nível crescente de pesquisa e de conhecimento do depósito, em: inferido, indicado e medido. $\mathrm{O}$ único parâmetro econômico aplicado no cálculo destes recursos é o teor de corte, fundamental para a definição prévia da economicidade de um depósito. A partir de estudos de viabilidade econômica do depósito considerando fatores econômicos, de mineração, metalúrgicos, mercadológicos, legais, ambientais, sociais e políticos, os recursos indicado e medido poderão vir a transformar-se em reservas provável e provada, respectivamente. Este é o modelo proposto, para adoção pelo DNPM, pelo grupo de trabalho criado pela Portaria $n^{\circ} 03$ de 24/10/90.

CLASSIFICACÃ̃O DE RESERVAS: CÓDIGO DE MINERAÇÃO O modelo de recursos medido, indicado e inferido, em ordem decrescente de pesquisa e conhecimento, pode ser correlacionável ao modelo de classificação de reservas, proposto pelo Código de Mineração. Assim, de acordo 


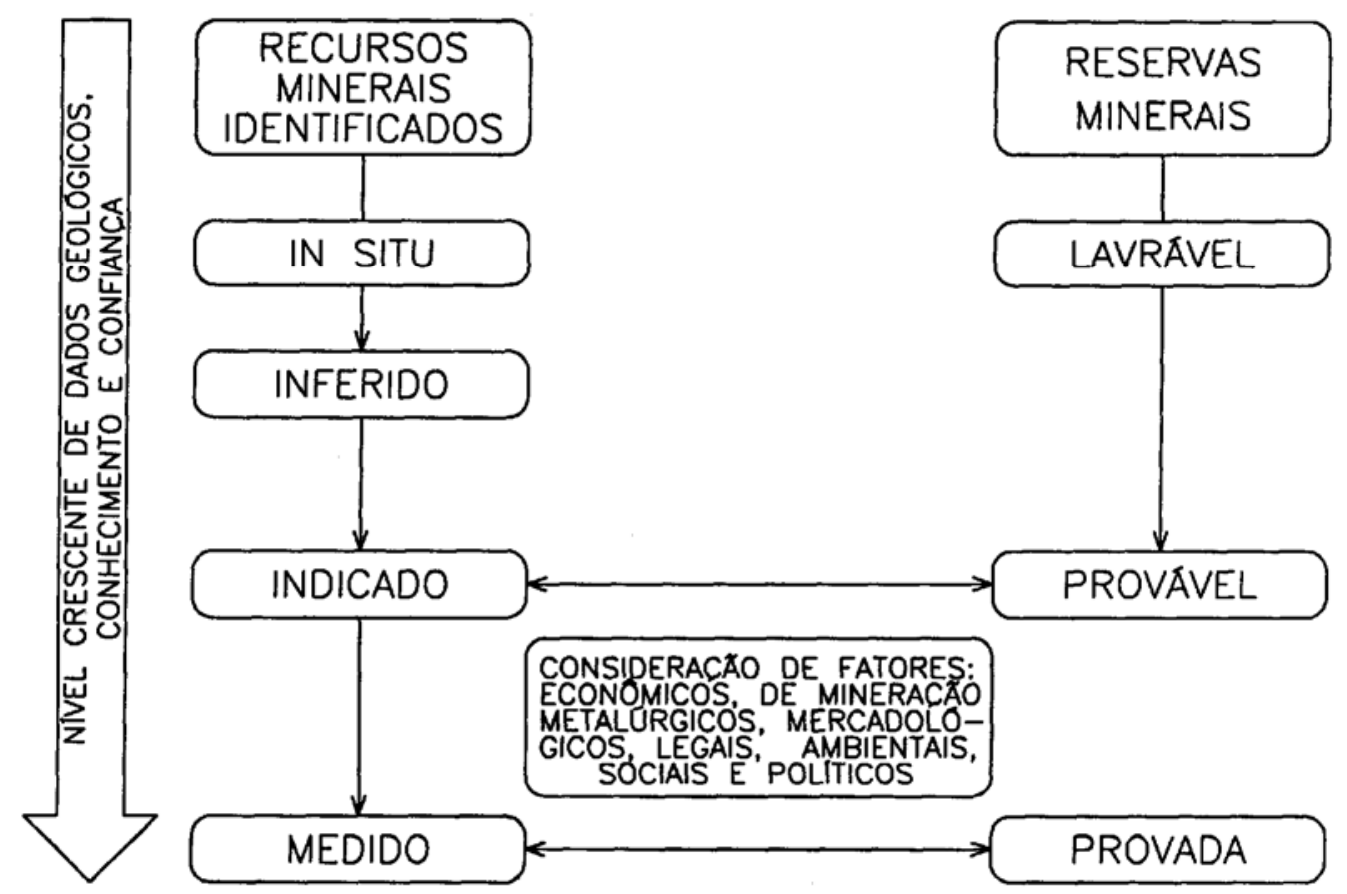

Figura 5 - Estimativa de reservas a partir de um modelo de recursos, segundo AIMM (J996).

Figure 5 - Reserve estimation from resource model, according to AIMM (1996).

com o Código de Mineração (DNPM 1987, pág. 103), considera-se:

Reserva medida: a tonelagem de minério computado pelas dimensões reveladas em afloramentos, trincheiras, galerias, trabalhos subterrâneos e sondagens, e na qual o teor é determinado pelos resultados de amostragem pormenorizada, devendo os pontos de inspeção, amostragem e medida estar tão proximamente espacejados e o caráter geológico tão bem definido que as dimensões, a forma e o teor da substância mineral possam ser perfeitamente estabelecidos. A tonelagem e o teor computados devem ser rigorosamente determinados dentro dos limites estabelecidos, os quais não devem apresentar variação superior, ou inferior a 20\% ( vinte por cento) da quantidade verdadeira;

Reserva indicada: a tonelagem e o teor do minério computados parcialmente de medidas e amostras específicas, ou de dados da produção, e parcialmente por extrapolação até distância razoável com base em evidências geológicas;

Reserva inferida: estimativa feita com base no conhecimento dos caracteres geológicos do depósito mineral, havendo pouco ou nenhum trabalho de pesquisa.

CLASSIFICAÇÃO DE RESERVAS: PORTARIA DNPM NO 03, DE 24/10/90 Recentemente, o DNPM, por meio da Portaria ${ }^{\circ} 03$ de 24/10/90, constituiu um Grupo de Trabalho para estabelecer as bases técnicas de um sistema permanente de quantificação do patrimônio mineral brasileiro, compreendendo as definições, terminologia, classificação e parametrização dos recursos e reservas minerais, bem como as rotinas a serem seguidas pela indústria mineral. Assim, o DNPM em 1992, edita o relatório do Grupo de Trabalho intitulado: "Bases técnicas de um sistema de quantificação do patrimônio mineral brasileiro", que propõe alterar o código e a legislação correlativa, conforme reproduz-se a seguir: a) Alterar as atuais definições de reservas medidas, indicadas e inferidas constantes $\mathrm{do}^{\wedge}$ Regulamento do Código de Mineração - RCM (Parágrafo Único do art. 26) para as definições de RECURSOS MEDIDOS, INDICADOS E INFERIDOS, nos termos do ANEXO 5.

b) Alterar a alínea " f" do inciso VIII do art. 22 do Código de Mineração - CM (correspondente à alínea " $h$ " do Art. 26 do RCM) para a expressão "indicação", como ilustra o Anexo 5.

c) Alterar a palavra "demonstração" da alínea " $\mathrm{h}$ ", inciso VIII do Art. 22 do CM (correspondente à alínea " g " do art. 26 do RCM) para a expressão "indicação", como ilustra o Anexo 5.

d) Acrescentar um inciso III do art. 39 do CM e um inciso IV ao art. 49 do RCM, com a seguinte redação: "Demonstração da exeqüibilidade econômica da lavra".

e) Complementar a alínea " $\mathrm{f}$ " do inciso VIII do Art. 22 do $\mathrm{CM}$ (correspondente à alínea " $\mathrm{h}$ " do art. 26 do RCM), exigindo-se no texto o Quadro de Parametrização dos Recursos Medidos, Indicados e Inferidos.

f) Inserir nos Capítulos "DA LAVRA" do CM e do RCM, as definições de RESERVAS PROVADAS E PROVÁVEIS, exigindo ainda que conste no Plano de Aproveitamento Econômico o Quadro de Parametrização destas reservas.

g) Modificar a redação do art. 31 do CM (correspondente ao art. 33 do RCM), renovando por mais um ano, a critério do DNPM, o prazo para requerer a lavra, desde que decorrido o prazo inicial, o requerente apresente justificativas de naturezas técnicas e econômica.

O modelo de classificação de recursos/reservas encontra-se na Figura 6.

A terminologia correspondente, ao modelo de classificação de recursos/reservas vigente no País, encontra-se no Anexo II. 




Figura 6 - Modelo de classificação de recursos/reservas proposto para adoção pelo Departamento Nacional da Produção Mineral (DNPM 1992).

Figure 6 - Resource/reserve classification model proposed for adoption by the National Department of Mineral Production (DNPM 1992).

ANÁLISE CRÍTICA DA CLASSIFICAÇÃO DE RECURSOS/RESERVAS PROPOSTA PELA PORTARIA NO 03 A classificação de recursos/reservas proposta ao DNPM (1992) representa uma evolução em relação à anterior, pela atualização das definições de recursos/reservas, bem como pela introdução do plano de aproveitamento econômico. Entretanto, as definições alternativas, reproduzidas a seguir, não são adequadas:

a) Recurso medido: alternativamente, recurso calculado com confiabilidade de pelo menos $95 \%$, para o qual o erro de estimação é no máximo de $20 \%$;

b) Recurso indicado: alternativamente, recurso calculado com confiabilidade de pelo menos $95 \%$, para o qual o erro de estimação é superior a $20 \%$ e inferior a $50 \%$;

c) Recurso inferido: alternativamente, recurso calculado com confiabilidade de pelo menos $95 \%$, para o qual o erro de estimação é superior a $50 \%$;

d) Reserva provada: alternativamente, reserva calculada por métodos geoestatísticos onde o bloco estimado tenha dimensões pertinentes à escala de produção e proporcionalidade com os alcances variográficos e tenha no mínimo uma amostra na sua auréola de influência, o que eqüivale a determinar as relações de covariância amostra(s)/bloco, bloco/bloco e amostra(s)/amostra(s);

e) Reserva provável: alternativamente, reserva calculada por métodos geoestatísticos onde o bloco estimado tenha dimensões pertinentes à escala de produção e proporcionali- dade com os alcances variográficos e nenhuma amostra em sua auréola de influência, o que eqüivale a atribuir à variância de krigagem do bloco o valor da variância a priori mais o valor do covariograma do bloco.

As definições alternativas (a), (b) e (c) não levam em consideração a variabilidade natural dos depósitos minerais, de acordo com as Tabelas 1 e 2, onde os coeficientes de variação são muito superiores aos níveis considerados nestas definições. Além disso, o nível de confiança de $95 \%$ para depósitos minerais é, em geral, muito elevado. O erro de estimativa, a um determinado nível de confiança, implica na variação permitida em torno da média, ou seja, a metade do intervalo de confiança. Dividindo-se o intervalo de confiança pela média tem-se o erro de estimativa ou a tolerância permitida para fins de classificação de recursos/reservas, como segue:

$$
E R R O=\frac{1 / 2 I C_{95 \%}}{\bar{X}}=\frac{S . t_{g l, n c}}{\bar{X} \sqrt{n}}
$$

Dessa relação tem-se o coeficiente de variação em função do erro de estimativa:

$$
C V=\frac{S}{\bar{X}}=\frac{E R R O * \sqrt{n}}{t_{g l, n c}}
$$


Assim, para ilustrar o efeito do nível de confiança na determinação do erro de estimativa, foram calculados os coeficientes de variação para as classes de recursos medido, indicado e inferido, de acordo com as definições alternativas (a), (b) e (c). Para esse fim, foram considerados blocos calculados sempre com oito amostras $(\mathrm{n}=8)$ e para três níveis de confiança (_):95, 90 e 80\%, conforme os resultados apresentados na Tabela 4.

Tabela 4 - Coeficientes de variação correspondentes aos erros de estimativa para as classes de recursos geológicos.

Table 4 - Coefficients of variation relative to the estimation errors for geological resources.

\begin{tabular}{|c|c|c|c|c|}
\hline & & \multicolumn{3}{|c|}{ coeficiente de variação (\%) } \\
\hline $\begin{array}{c}\text { classes de } \\
\text { recursos }\end{array}$ & $\begin{array}{c}\text { erro de } \\
\text { estimativa (\%) }\end{array}$ & $\alpha=95 \%$ & $\alpha=90 \%$ & $\alpha=80 \%$ \\
\hline Medido & 20 & 25 & 30 & 40 \\
\hline Indicado & $20-50$ & $25-60$ & $30-75$ & $40-100$ \\
\hline Inferido & $>50$ & $>60$ & $>75$ & $>100$ \\
\hline
\end{tabular}

Como se pode verificar, os valores de coeficientes de variação obtidos não permitem classificar todos os tipos de depósitos minerais, em função da variabilidade natural dos mesmos. Além disso, o nível de confiança de 95\% é aplicável somente a depósitos minerais extremamente homogêneos na forma e na distribuição de teores. Talvez o nível de confiança igual a $90 \%$ fosse mais apropriado para materiais geológicos (tal como proposto por Wellmer 1983), mas mesmo assim a classificação será possível somente a alguns tipos de depósitos minerais. Por isso, o Código Australiano para Comunicação de Recursos Minerais Identificados e Reservas Minerais não propõe o uso de erros de estimativa para a classificação de recursos/reservas.

Considerando que recurso medido é correlacionável à reserva provada e recurso indicado à reserva provável, não há motivos para propor definições alternativas diferentes, pois o conhecimento e confiança geológicos são os mesmos para essas classes de recursos/reservas, ou seja, não há necessariamente um detalhamento da pesquisa mineral. Não se justifica também propor o uso de técnicas geoestatísticas para avaliação de reservas e não necessariamente para recursos.

A definição alternativa (d) permite que se classifique um bloco como reserva provada se o mesmo for calculado com no mínimo uma amostra em sua auréola de influência. A Figura 7 ilustra como a aplicação da definição alternativa (d) permite atribuir a classe de reserva provada para blocos, calculados com 1 e 6 amostras na auréola de influência e, portanto, de diferentes graus de confiança geológica. Assim, verifica-se que esta definição alternativa é inadequada para o rigor que a classe de reserva provada exige.

Por fim, a definição alternativa (e), não exige uma única amostra sequer na auréola de influência do bloco de cubagem e, portanto, permite determinar o teor do bloco como média aritmética das amostras situadas no campo aleatório do variograma, classificando a reserva assim obtida como provável. Assim, blocos na periferia do depósito, bem como em regiões subamostradas serão classificados automaticamente como blocos de reserva provável, independente da densidade relativa das amostras, que deveriam ser consideradas bloco a bloco.

\section{RECOMENDAÇÕES PARA O CÁLCULO E CLASSI-} FICAÇÃO DE RECURSOS/ RESERVAS Segundo Popoff (1966), o procedimento de cálculo de recursos/reservas é um trabalho técnico consistindo em várias operações, que em ordem de execução são avaliações geológicas,

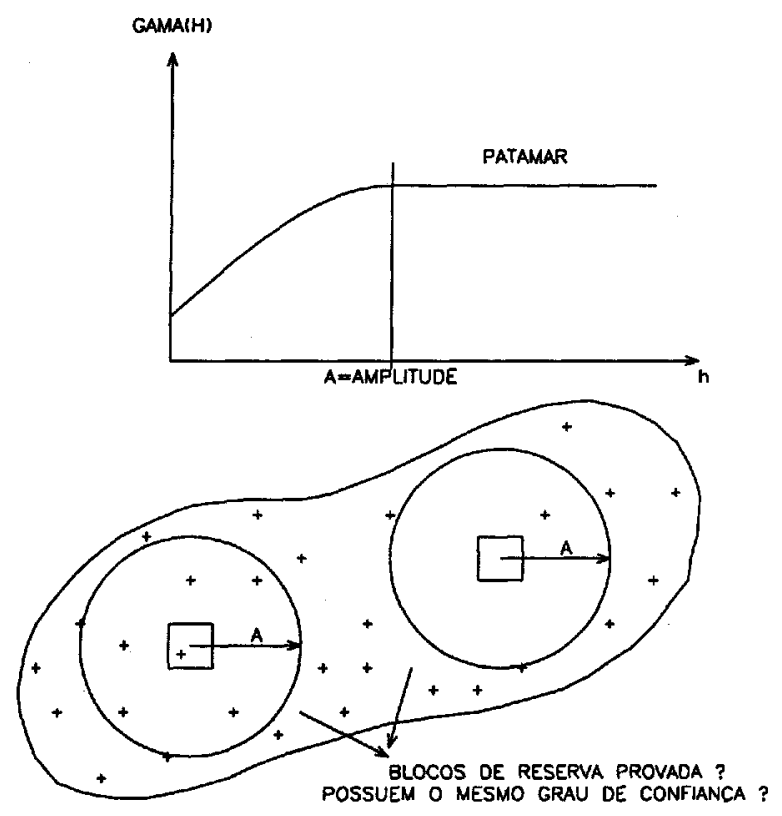

Figura 7 - Desenho mostrando situações possíveis para cálculo de reserva provada usando a definição alternativa (d).

Figure 7 - Schematic drawing showing the possible situations for computing proved reserve using the alternative definition (d).

avaliações do método de pesquisa e amostragem, avaliação dos dados de pesquisa, delineação do corpo mineral e seleção de um método apropriado para o cálculo de reservas. Feitas as avaliações recomendadas por Popoff (1966), o cálculo de reservas consiste na determinação de teores e volumes dentro do corpo geológico conhecido.

Avaliações geológicas As avaliações geológicas visam a determinação dos limites do corpo de minério. Os principais controles geológicos utilizados nestas avaliações são: estruturais (p. ex. falhas, fraturas, etc.), mineralógicos (tipos de minerais de minério) e litológicos (tipos de rochas, graus de alteração, fraturamento, etc.).

Toda a estimativa de volumes, massas e teores de um depósito, segundo Vallée \& Cote (1992), deve ser baseada em observações sistemáticas e interpretações da geologia (litologia e estrutura) e da mineralização (mineralogia, controles, distribuição e continuidades).

A aquisição de dados geológicos deve ser sistemática e sempre que possível quantitativa (Vallée \& Cote 1992).

Da mesma forma, a interpretação das informações geológicas deve ser sistemática para definir as continuidades geológicas e estruturais, bem como os controles de mineralização (Vallée \& Cote 1992).

A continuidade da mineralização reflete-se:

- no cálculo de reservas, onde "o grau de continuidade de valores dentro de um depósito irá influenciar fortemente a escolha dos parâmetros de interpolação. Em depósitos com baixa continuidade, não haveria necessidade de refinar esses parâmetros. Contudo, em depósitos com boa continuidade, distâncias de pesquisa apropriadas, tendências e, possivelmente, fatores de anisotropia serão determinados para estender valores apropriadamente", in Bass (1987); 
- no beneficiamento, onde as respostas aos processos de recuperação de minério estão freqüentemente relacionadas a variações litológicas e mineralógicas;

Avaliações do método de pesquisa e amostragem Nesta etapa os métodos de pesquisa utilizados, bem como a amostragem realizada devem ser avaliados quanto aos seguintes aspectos, segundo Handley et al. (1987):

- técnica de sondagem: verificar se o tipo de sondagem utilizado é adequado ou não para uma amostragem confiável;

- técnica de amostragem: verificar como foi feita a amostragem e a quantidade analisada, com atenção à preparação para redução da amostra.geológica;

Segundo Diehl \& David (1982), todas as comunicações de qualidade ou quantidade de recursos minerais são baseadas na extensão das informações dos pontos de amostragem para áreas ainda desconhecidas dentro do corpo de minério (o tamanho dessas amostras é geralmente muito pequeno comparado às dimensões do depósito). Ainda segundo aqueles autores, em termos estatísticos, os parâmetros reais, mas desconhecidos, do depósito ou de partes do mesmo foram estimados a partir de dados básicos (testemunhos de sondagem, amostras de canal, etc.). Assim, segundo Diehl \& David (1982), as estimativas estão sujeitas a erros, cuja magnitude depende: a) da natureza e da quantidade de informação dos pontos de amostragem; b) da regularidade espacial da mineralização; c) do volume de minério para ser estimado; e d) da qualidade do método de estimativa.

Avaliação dos dados de pesquisa As informações disponíveis da prospecção e pesquisa mineral são avaliadas criticamente nos seguintes aspectos (Handley et al. 1987):

- densidade dos dados: verificar se a densidade de amostras é suficiente ou não para garantir a continuidade da mineralização. A malha de sondagem empregada deve ser compatível com a dimensão e natureza do depósito mineral em estudo. Além disso, se fosse reconhecida a existência de uma possível anisotropia na distribuição de teores, na fase inicial de sondagem, a sondagem poderia ser redirecionada para melhorar a densidade de informações na direção de maior variação.

- exatidão da localização dos pontos de amostragem: certificar-se da posição da amostra e seu efeito no cálculo de reservas. A localização de amostras do depósito reflete-se diretamente na geometria do bloco de cubagem (no caso de métodos convencionais) e, conseqüentemente, nas reservas obtidas;

- recuperação do testemunho na zona mineralizada: verificar como foi determinada a recuperação e com que freqüência. $O$ testemunho geralmente se expande quando colocado na caixa, especialmente se o testemunho for quebrado. Quando o testemunho for extremamente macio e friável ou muito quebrado, haverá necessidade de medir a recuperação no próprio barrilete antes de colocá-lo na caixa;

- densidade aparente, peso específico ou fator tonelagem: é o dado cuja obtenção é mais difícil, especialmente em material friável ou alterado, e de maior importância, pois o erro na sua determinação reflete-se na mesma proporção das reservas calculadas. Apesar da importância deste parâmetro na avaliação de reservas, ele não é determinado sistematicamente durante a pesquisa mineral, mas sim em alguns poucos pontos da jazida, os quais são então utilizados para se calcular um valor médio a ser utilizado para todo o depósito. Observe-se que os valores de densidade aparente poderão variar bastante no depósito, principalmente naqueles com alta variabilidade natural nos teores. $\mathrm{Na}$ realidade, assim como se obtém um modelo de distribuição de teores no depósito, dever-se-ia obter também um modelo de distribuição de densidades aparentes para todo o depósito. Isto implica que sistematicamente, após a descrição do testemunho de sondagem, parte destinada às análises químicas deveria ser ensaiada para determinação da densidade aparente.

- qualidade das análises: verificar se os resultados são precisos ou imprecisos por viés ou pura aleatoriedade.

Delineação do corpo mineral A análise e interpretação dos dados disponíveis permitem determinar a forma, os limites e as dimensões de um depósito. Os limites primários de um depósito são estabelecidos pela litologia, acamamento, estruturas e variações bruscas no teor, enquanto os limites secundários estão relacionados a variações graduais nos teores, limites irregulares da mineralização ou contornos, cujos detalhes não podem ser seguidos na interpretação e lavra (Vallée \& Cote 1992). Tonelagens de minérios são obtidas a partir da aplicação da densidade aparente em volumes delimitados nos corpos geológicos. Assim, é de importância fundamental o conhecimento de fatores geológicos e geométricos do depósito, de tal modo que os limites de mineralização possam ser estabelecidjos de maneira segura e, assim, a forma do corpo de minério. E preciso ressaltar que a delineação do corpo de minério, independente do método de cálculo de reservas, seja ele convencional ou computacional, é feita manualmente, a partir de plantas e seções geológicas, pelo geólogo responsável pela pesquisa.

Com relação à geometria dos corpos de minério, estes podem ser classificados dentro dos seguintes tipos morfológicos (Kreiter 1968);

- eqüidimensionais: compreendem os corpos com dimensões mais ou menos iguais em todas as direções, tais como bolsões (por ex. mineralizações sulfetadas e depósitos escarníticos); grandes stockworks (por ex. depósitos de cassiterita, de crisotila e cobre porfirítico); e na forma de colmeia (por ex. depósitos de domos salinos e corpos metassomáticos hidrotermais);

- tabulares: incluem corpos com uma dimensão pequena e duas dimensões maiores. Nesses tipos podem incluir-se veios ou filões, camadas, lentes, diques, sills e outros;

- alongados: incluem corpos com uma dimensão maior que as outras duas, tais como chaminés e corpos com formas semelhantes.

Seleção de um método apropriado para o cálculo de reservas $O$ levantamento e análise das informações obtidas na pesquisa do depósito, já permitem selecionar um método adequado para o cálculo de reservas. Os parâmetros decisivos na escolha do método são:

- geometria do corpo de minério;

- modelo geológico do depósito;

- amostras disponíveis;

- distribuição das amostras;

- variabilidade dos teores.

Existem atualmente diversos métodos para avaliação de reservas, os quais podem ser classificados como:

- métodos convencionais;

- métodos computacionais.

Os métodos convencionais foram desenvolvidos e utilizados desde os primórdios da mineração e ainda hoje são 
empregados no cálculo de reservas. Nesse grupo, de acordo com revisão de Popoff (1966), encontram-se:

- método dos blocos análogos ou geológicos;

- método dos blocos de lavra;

- método dos perfis;

- métodos analíticos.

Assim, calculando-se os recursos/reservas, aplicando-se os métodos convencionais, as classes de reservas medida/ provada e indicada/provável só podem ser atribuídas a blocos de cubagem que atendam aos requisitos de continuidade declarados na Portaria 03 do DNPM. Nesse caso, os blocos de cubagem possuem geometria variável de acordo com a densidade e distribuição dos pontos de amostragem, bem como do método utilizado. A Figura 8 apresenta as configurações possíveis de blocos de cubagem para os métodos convencionais. Assim, a classificação de recursos/reservas processa-se bloco a bloco, atribuindo-se a classe medida/provada àqueles blocos, cujos pontos de amostragem permitem assegurar a continuidade da mineralização nos mesmos.

Os métodos computacionais, assim denominados por dependerem da utilização de computadores na resolução de seus algoritmos, atualmente existentes para fins de avaliação de reservas são:

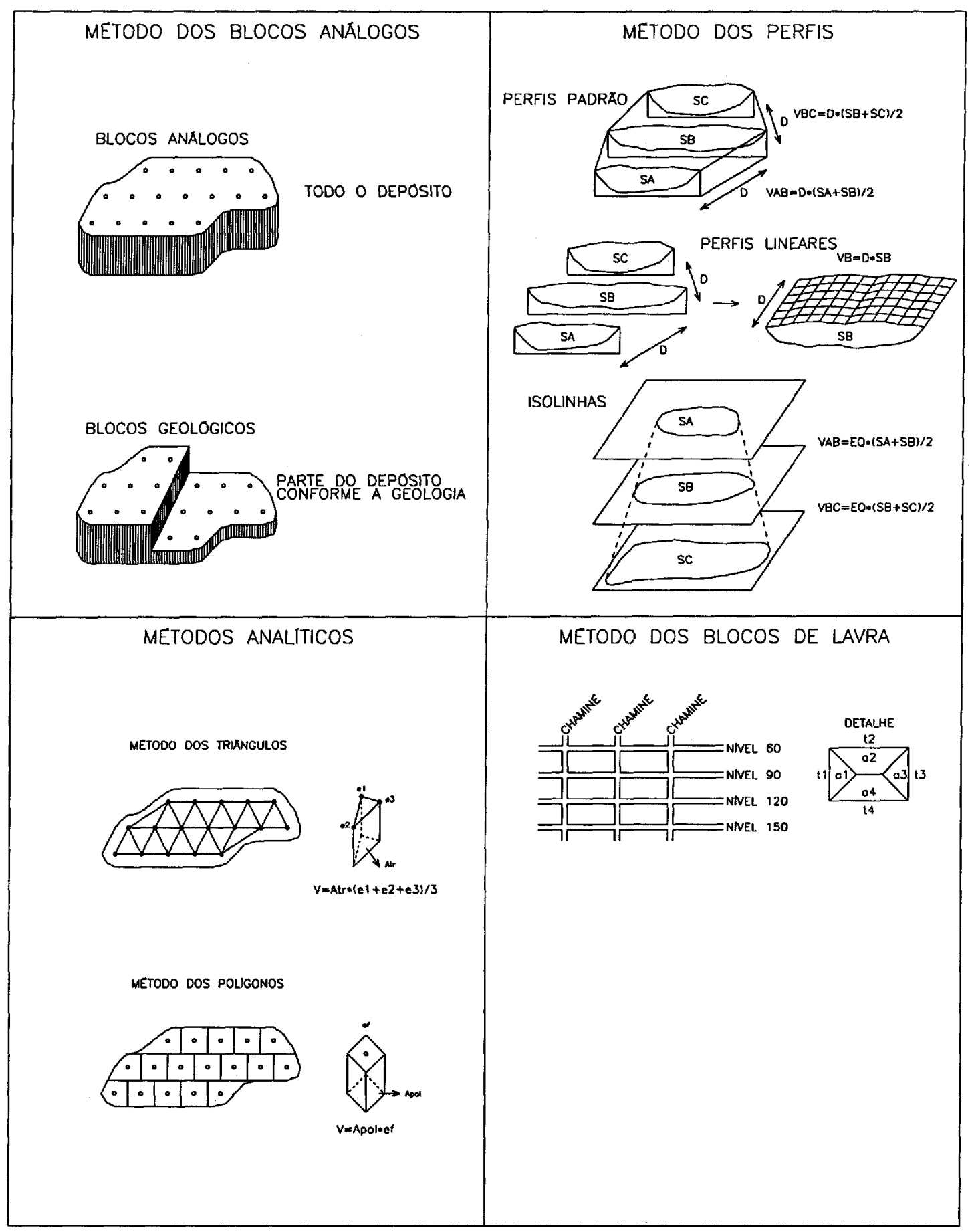

Figura 8 - Configurações possíveis de blocos de cubagem para os métodos convencionais (desenhos esquemáticos baseados em Conde \& Yamamoto 1995).

Figure 8 - Configurations of possible estimation blocks according to conventional methods (schematic drawings based on Conde \& Yamamoto 1995). 
- ponderação pelo inverso da potência da distância;

- métodos geoestatísticos.

O método da ponderação pelo inverso da potência da distância é efetivamente o primeiro desenvolvido para ser utilizado em computadores, pois envolve operações aritméticas que não poderiam ser facilmente resolvidas manualmente.

Os métodos geoestatísticos foram desenvolvidos na década de 60 e efetivamente empregados na década seguinte. Estes métodos fazem uso intensivo de computadores, muito embora em seu início tenham sido utilizados ábacos das funções auxiliares para os seus cálculos. Dentre os vários métodos geoestatísticos existentes, genericamente denominados de krigagem, o método da krigagem ordinária será considerado neste artigo, pois pode resolver a maioria dos problemas em avaliação de reservas.

O cálculo de recursos/reservas por métodos computacionais é feito a partir da subdivisão do depósito em pequenos blocos de cubagem, cujas dimensões devem ser compatíveis com a densidade de pontos de amostragem. Ao conjunto de blocos de cubagem denomina-se modelo tridimensional de blocos, como ilustrado na Figura 9.

Em termos práticos, as dimensões ideais do bloco deveriam ser iguais ao espaçamento médio dos pontos de amostragem, pois conteriam em média um ponto de amostragem em seu interior, o que asseguraria um alto grau de certeza geológica sobre o conteúdo dos mesmos. Contudo, quando isto não for possível, pode-se adotar até no mínimo a metade do espaçamento médio. Assim, por exemplo, se a malha de amostragem é de $100 x 100 m$, os blocos de cubagem podem ser de no mínimo 50x50m. Segundo Vallée \& Cote (1992), a krigagem de blocos com dimensões muito menores que a metade da malha de amostragem deveria ser evitada, pois tais estimativas exibem extrema variabilidade. As relações entre as dimensões dos blocos e malhas de amostragem só são válidas se for possível estabelecer a continuidade da mineralização entre os pontos de amostragem, pois caso contrário, a amostragem seria indicativa de mineralização e os blocos assim avaliados deveriam ser classificados como recursos indicados.

Da mesma forma, como nos métodos convencionais, a classificação de reservas processa-se bloco a bloco, o qual será calculado se, e somente se. estiver dentro dos limites de

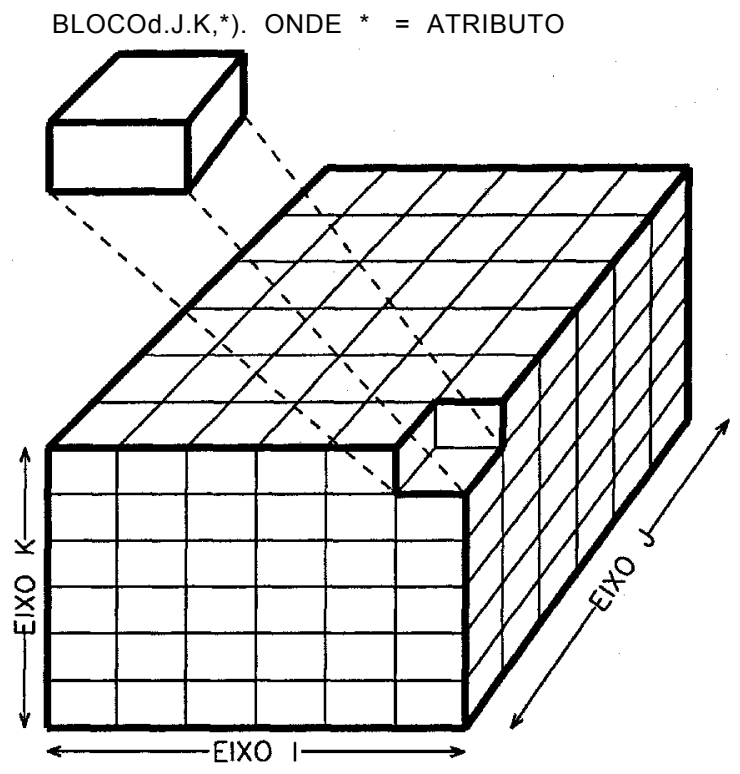

Figura 9 - Modelo tridimensional de blocos de um depósito hipotético, segundo Springett (1990).

Figure 9 - Three-dimensional model of blocks for hypothetical deposit, after Springett (1990). mineralização estabelecidos pelo geólogo em plantas e seções. Além disso, é necessário reconhecer a posição dos blocos no depósito, pois, segundo Roy lê (1977), blocos de reservas de altas categorias de certeza estão situados dentro do domínio da amostragem no corpo de minério e, por isso, apresentam baixos valores de variância de krigagem. Por outro lado, ainda segundo aquele autor, os blocos periféricos aos domínios de amostragem apresentarão altas variâncias de krigagem, além de outra fonte de incerteza que é a definição do limite minério/ estéril na borda do corpo de minério. Recomenda-se a utilização criteriosa da variância de krigagem associada a um parâmetro geológico para fins de classificação de reservas em um depósito em particular. Porém, não se recomenda a utilização exclusiva dessa medida de dispersão geoestatística para fins de classificação de reservas como proposta por vários autores, entre os quais cita-se Diehl \& David (1982) e Wellmer (1983), pois estes esquemas, não levando em consideração a variabilidade intrínseca do depósito, são totalmente inadequados.

Um outro problema a considerar no caso de cálculo de reservas em blocos de cubagem, por meio dos métodos computacionais, é a distância máxima dos pontos de amostragem em relação ao bloco de cubagem. Muitas vezes a distância máxima não pode ser estabelecida somente em termos da amplitude do variograma, mas também levando-se em consideração a dimensão do bloco. Estes cuidados justificam-se para evitar a utilização de pesos negativos da krigagem ordinária com conseqüências indesejáveis (teores e espessuras negativos), devido ao efeito de sombreamento que as amostras mais próximas causam em relação às mais distantes (Barnes \& Johnson 1984 e Herzfeld 1989). A Figura 10, baseada em Bubenicek \& Haas (1969), mostra um conjunto de blocos para ilustrar o conceito de distância máxima em função do lado do bloco.

Segundo Bubenicek \& Haas (1969), o bloco a ser estimado é chamado bloco central, o primeiro anel de 8 blocos em torno do bloco central é chamado de primeira auréola e o segundo anel de 16 blocos é chamado de segunda auréola. Na prática, esses autores estabelecem um limite de duas aureolas em torno do bloco central para a krigagem de zonas mineralizadas e uma auréola para a krigagem de zonas de borda do corpo de minério.

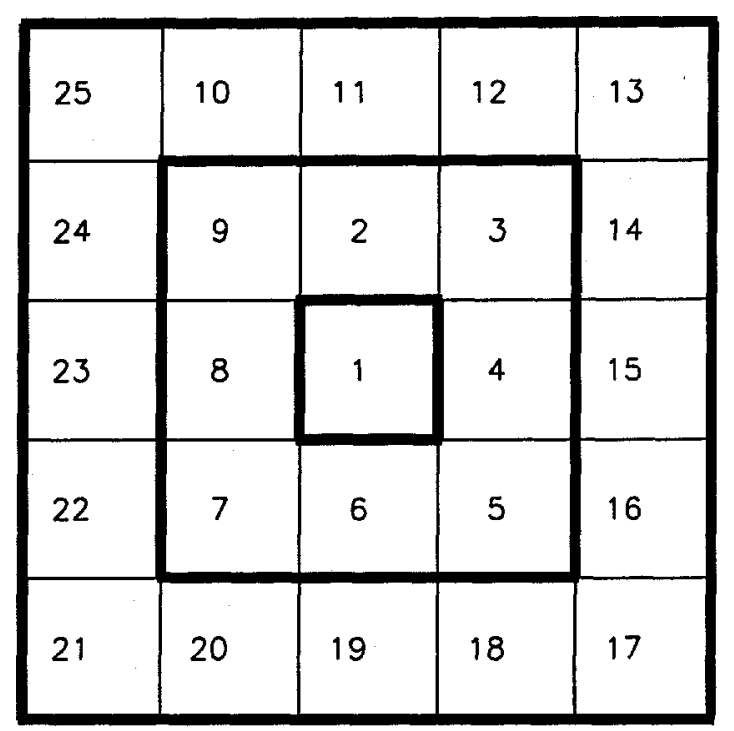

Figura 10- Localização do bloco central e blocos periféricos, segundo Bubenicek \& Haas (1969).

Figure 10 - Localization of the central and peripheral blocks, according to Bubenicek \& Haas (1969). 
Por fim, recomenda-se, sempre que possível, a utilização dos métodos geoestatísticos para avaliação de recursos/reservas, pois fazem melhor uso da informação disponível. Assim, o bloco pode ser classificado como recurso medido ou reserva provada se o mesmo for avaliado com no mínimo uma amostra em seu interior e três a quatro amostras dentro da amplitude do variograma. Contudo, para a classe de recurso indicado ou reserva provável, pode-se avaliar o bloco com no mínimo três a quatro amostras situadas na amplitude do variograma (blocos situados nestas condições situam-se geralmente na borda do corpo de minério).

CONSIDERAÇÕES FINAIS Os modelos de classificação de reservas atualmente aceitos pela indústria mineral diferenciam o recurso geológico in situ da reserva mineral aproveitável economicamente ao tempo de sua determinação. Assim, a comprovação de economicidade permite a transformação de recursos em reservas. Nesse sentido, os recursos inferidos, devido ao baixo nível de informação e baixo nível de confiança na sua existência, devido à baixa probabilidade de comprovação, não são mais considerados para as estimativas de reservas minerais e, conseqüentemente, para os estudos de viabilidade econômica do projeto de mineração. Os estudos de viabilidade econômica devem levar em consideração não somente os fatores teor e recuperação na usina, mas também os custos de mineração, mercadológicos, legais, ambientais, sociais e políticos.

Levando-se em consideracão que depósitos minerais podem exibir uma variabilidade intrínseca, resultante da interação dos processos geológicos responsáveis pela sua gênese, a classificação de recursos deve ser feita com base na densidade relativa das amostras e, sobretudo, pela garantia de continuidade da mineralização entre as amostras. Contudo, nem sempre é possível garantir a continuidade da mineralização, principalmente no caso de depósitos de metais raros com variações aleatórias (presença do efeito pepita). Nesses casos, não é possível estabelecer classes de recursos de alta confiabilidade geológica, como foi muito bem demonstrado por Diatchkov (1994). A classificação de Diatchkov (1994) é extremamente pratica, pois mostra claramente que, para depósitos com alta variabilidade natural, os trabalhos de pesquisa não permitem detalhar as reservas para classes de maior confiança geológica.

A Portaria DNPM n ${ }^{\circ} 03$, de 24/10/90 constituiu um grupo de trabalho que estabeleceu as bases técnicas de um sistema permanente de quantificação do patrimônio mineral brasileiro, compreendendo as definições, terminologia, classificação e parametrização dos recursos e reservas minerais, bem como as rotinas a serem seguidas pela indústria mineral. Este grupo de trabalho propôs a alteração do código e da legislação correlativa e propõe estabelecer um novo modelo para classificação de recursos/reservas. Trata-se de um modelo atualizado e aceito internacionalmente, porém como ficou demonstrado neste trabalho as definições alternativas propostas para os recursos/reservas não são adequadas. Assim, para o aperfeiçoamento deste modelo há necessidade de revisar as definições e terminologia adotadas.

O trabalho de avaliação e classificação de recursos/reservas é uma atividade técnica, que deve ser conduzida por um profissional competente, que consiste em várias operações: avaliações geológicas, avaliações do método de pesquisa e amostragem, avaliação dos dados de pesquisa, delineação do corpo mineral e seleção de um método apropriado para o cálculo de reservas. Por fim, com a escolha do método para o cálculo de recursos/reservas, procede-se à classificação de reservas dos blocos de cubagem, que deve ser seguida bloco a bloco, não se recomendando procedimentos automáticos para esse fim.

Finalmente, este trabalho apresentou uma revisão sobre avaliação e classificação de recursos/reservas, com o objetivo de representar uma contribuição à indústria brasileira de mineração.

Agradecimentos Os autores expressam seus mais sinceros agradecimentos ao Prof. Dr. João Batista Moreschi pela criteriosa revisão no manuscrito, bem como ao Prof. Dr. Thomas R. Fairchild pela revisão da versão do resumo para o inglês.

\section{REFERÊNCIAS}

AUSTRALASIAN INSTITUTE OF MINING AND METALLURGY-AIMM 1996. Australasian code for reporting of identified mineral resources and ore reserves. The AusIMM Bulletin .(4):1-19.

BARNES, R.P. \& JOHNSON, T.B. 1984. Positive kriging. In: Verly el al. (eds) Geostatistics for natural resources characterization. Reidel. Part I,p.231-244.

BASS, C.B. 1987. Reserve data for project planning. In: Resources and Reserves Symposium, Sydney, 1987. Proceedings-Sydney, The Australasian Institute of Mining and Metallurgy, p.81-87.

BUBENICEK, L. \& HAAS, A. 1969. Method of calculation of the iron ore reserves in the Lorraine deposit. In: The decade of digital computing in the mineral industry. The American Institute of Mining, Metallurgical and Petroleum Engineers, Inc. New York. p. 179-210.

CONDE, R. P. \& YAMAMOTO, J. K. 1995. Avaliação de reservas por métodos convencionais: um estudo de caso na Mina de Canoas 2 (PR). Boi. IG-USP, Ser. Cient., 26:13-28.

DEPARTAMENTO NACIONAL DA PRODUÇ̃̃O MINERAL -DNPM, 1987. Código de Mineração e legislação correlativa. Brasília, DNPM $333 \mathrm{p}$.

DEPARTAMENTO NACIONAL DA PRODUÇÃO MINERAL -DNPM, 1992. Bases técnicas de um sistema de quantificação do patrimônio mineral brasileiro. Brasília, DNPM. 28p. (Relatório do Grupo de Trabalho, Portaria $n^{\circ} 03$ de 24/10/90, da Secretaria Nacional de Minas e Metalurgia)

DIATCHKOV, S.A. 1994. Principles of classification of reserves and resources in the CIS countries. Min. Eng., 46(3):214-217.

DIEHL, P. \& DAVID, M. 1982. Classification of ore reserves/resources based on geostatistical methods. CIM Bull., 75(838): 127-136.

FROIDEVAUX, R. 1982. Geostatistics and ore reserve classification. CIM Bull. 75(843):77-83.
GROSSI SAD, J.H. 1986. Fundamentos sobre a variabilidade dos depósitos minerais. Rio de Janeiro, DNPM/CPRM-GEOSOL. 141p.

GROSSI SAD, J.H. \& VALENTE, J.M.G.P. 1996. Reservas e recursos minerais - uma revisão. In: Seminário Nacional sobre "Informática ern Mineração: Pesquisa, Lavra e Beneficiamento Mineral", 6, Belo Horizonte, 1996. Atas..Belo Horizonte, IBRAM, p.70-92.

HANDLEY, G.A.; LEWIS, R.W.; WILSON, I. 1987. The collection and management of ore reserve estimation data. In: Resources and Reserves Symposium, Sydney, 1987. Proceedings..Sydney, The Australasian Institute of Mining and Metallurgy, p.27-30.

HERZFELD, U.C. 1989. A note on programs performing kriging with nonnegative weights. Math. Geol., 21(3):391-393.

JEFFREYS, J.T. 1987 A methodology for estimating reserves from resource models. In: Resources and Reserves Symposium, Sydney, 1987. Proceedings-Sydney, The Australasian Institute of Mining and Metallurgy, p.65-72.

KREITER, V.M. 1968. Geological prospecting and exploration. Moscow, MIR Publishers. 383p.

MACHADO, I. 1989. Recursos minerais-Política e sociedade. São Paulo, Edgard Blücher. 410p.

NOBLE, A.C. 1993. Geologic resources vs. ore reserves. Min. Eng., 45(2): $173-176$.

POPOFF, C.C. 1966. Computing reserves of mineral deposits: principles and conventional methods. Washington, Bureau of Mines. 113p. (I.C. 8283).

ROYLE, A.G. 1977. How to use geostatistics for ore reserve classification. World Min., p. 52-55.

SPRINGETT, M. 1990. Computer applications in mine development. In: COMPUTER TREATMENT OF EXPLORATION AND MINING DATA: DO'S AND DON'TS, Ontario, 1990. Proceedings...Ontario, PROSPECTORS AND DEVELOPERS ASSOCIATION OF CANADA, p. 240-247. 
VALLÉE, M. \& COTE, D. 1992. The guide to the evaluation of gold deposits: integrating deposit evaluation and reserve inventory practices. CIM Bull.,85(957):50-61.

WELLMER, F.W. 1983. Classification of ore reserves by geostatistical methods. ERZMETALL, 36(7/8):315-321.

MANUSCRITO A905

Recebido em20 de janeiro de 1997

Revisão dos autores em 07 de maio de 1997

Revisão aceita em 08 de maio de 1997

\section{Anexo I: Terminologia do Código Australiano para Comunicação de Recursos Minerais Identificados e Reservas Minerais.}

1) Um Recurso Mineral é definido como uma ocorrência mineral identificada in situ, a partir da qual minerais úteis ou valiosos podem ser recuperados. Recursos Minerais podem ser subdivididos em:

- Recursos Minerais Inferidos;

- Recursos Minerais Indicados;

- Recursos Minerais Medidos.

2) O termo Recurso Mineral Inferido significa um Recurso Mineral inferido a partir de evidências geocientíficas, furos de sondagem, aberturas subterrâneas ou outros procedimentos de amostragem, onde a falta de dados é tal que a continuidade não pode ser declarada com confiança e onde os dados geocientíficos podem não ser conhecidos com um razoável nível de confiabilidade.

3) O termo Recurso Mineral Indicado significa um Recurso Mineral amostrado por furos de sondagem, aberturas subterrâneas ou outros procedimentos de amostragem em pontos demasiadamente espaçados para garantir a continuidade, mas próximos suficiente para dar uma razoável indicação de continuidade e onde os dados geocientíficos são conhecidos com um razoável nível de confiabilidade. A estimativa de Recurso Mineral Indicado será baseada em mais dados e, portanto, será mais confiável que a estimativa de Recurso Mineral Inferido.

4) O termo Recurso Mineral Medido significa um Recurso Mineral bloqueado e testado por furos de sondagem, aberturas subterrâneas ou outros procedimentos de amostragem em pontos, pouco espacados, suficientes para confirmar a continuidade e onde os dados geocientíficos são seguramente conhecidos. Uma estimativa de Recurso Mineral Medido será baseada em uma quantidade substancial de dados confiáveis, cuja interpretação e avaliação permite uma clara determinação das formas, tamanhos, densidades e teores.

5) A escolha da categoria apropriada de Recurso Mineral depende da quantidade e qualidade dos dados disponíveis e o nível de confiança que está associado àqueles dados. A categoria apropriada de Recurso Mineral deve ser determinada por pessoa competente.

6) Uma Reserva Mineral é definida como parte de Recursos Minerais Medido ou Indicado que poderia ser lavrada, inclusive com diluição, e a parti da qual minerais úteis ou valiosos poderiam ser recuperados economicamente sob condições realisticamente assumidas ao tempo da comunicação. As Reservas Minerais são subdivididas em:

\section{- Reservas Minerais Prováveis; e}

- Reservas Minerais Provadas.

As estimativas de Reservas Minerais são derivadas de estimativas de Recursos Minerais modificadas por fatores econômicos, de mineração, metalúrgicos, mercadológicos, legais, ambientais, sociais e governamentais.

7) O termo Reserva Mineral Provável significa uma Reserva Mineral expressa em termos de tonelagens/volume lavráveis e teor onde o Recurso Mineral Identificado correspondente foi definido por sondagens, amostragem ou escavação (incluindo extensões além das aberturas reais e furos de sondagem) e onde os fatores geológicos que controlam o corpo de minério são conhecidos com confiança suficiente parta que o Recurso Mineral seja categorizado como Indicado.

8) O termo Reserva Mineral Provada significa uma Reserva Mineral expressa em termos de tonelagens/volume mineráveis e teor na qual o Recurso Mineral Identificado foi definido em três dimensões por escavações ou sondagens (incluindo pequenas extensões além das aberturas reais e furos de sondagem), e onde os fatores geológicos que limitam o corpo de minério são conhecidos com suficiente confiança para que o Recurso Mineral seja categorizado como Medido.

9) A escolha da categoria apropriada de Reserva Mineral é determinada pela classificação do Recurso Mineral correspondente e deve ser feita por pessoa competente.

\section{Anexo II: Terminologia do modelo de classificação de recursos/reservas adotado pelo Departamento Nacional da Produção Mineral (DNPM 1992).}

1) RECURSO ECONÔMICO: concentração de materiais sólidos, líquidos ou gasosos identificada in situ, aflorante ou subterrânea, quantificada exclusivamente com base em dados geocientíficos e um teor de corte geológico, da qual podem ser recuperadas substâncias úteis e valiosas. Este conceito implica numa indicação preliminar de economicidade, ou seja, de perspectivas razoáveis de aproveitamento econômico, a ser comprovado posteriormente. Os recursos podem ser classificados como: MEDIDO, INDICADOSteriormente. Os recur

2) RECURSO MEDIDO: recurso comprovado por sondagens, escavações subterrâneas e outras formas de amostragem em pontos poucos espaçados de modo a assegurar a sua continuidade e cujos dados geocientíficos (forma, dimensão, densidade, qualidade e teor) são conhecidos com confiabilidade ou, ALTERNATIVAMENTE, recurso calculado com confiabilidade de pelo menos $95 \%$, para o qual o erro de estimação é no máximo de $20 \%$

3) RECURSO INDICADO: recurso amostrado por sondagens, escavações subterrâneas e outras formas de amostragem em pontos com espaçamento insuficiente para assegurar a continuidade, porém suficiente para um indicação razoável da mesma e cujos dados geocientíficos (forma, dimensão, densidade, qualidade e teor) são conhecidos com razoável nível de confiabilidade ou, ALTERNATIVAMENTE, recurso calculado com confiabilidade de pelo menos $95 \%$, para o qual o erro de estimação é superior a $20 \%$ e inferior a $50 \%$

4) RECURSO INFERIDO: recurso estimado com base em inferências a partir de evidências geológicas, sondagens, escavações subterrâneas e outras formas de amostragem, onde ainda faltam informações de testes e amostragem que venham a permitir uma estimativa sistemática mais confiável, ou, ALTERNATIVAMENTE, recurso calculado com confiabilidade de pelo menos $95 \%$, para o qual o erro de estimação é superior a 50\%
5) RESERVA: parte ou totalidade de um recurso medido ou indicado, que pode ser lavrada e da qual podem ser recuperadas economicamente substâncias minerais úteis e valiosas sob condições consideradas realistas à época de avaliação técnico-econômica. É oriunda das estimativas prévias dos recursos econômicos nas quais devem necessariamente serem considerados fatores econômicos, técnicos (da mineração e da metalurgia), mercadológicos, ambientais, sociais, governamentais e legais. As reservas são classificadas como: PROVADA E PROVÁVEL.

6) RESERVA PROVADA: parte ou totalidade de um recurso medido economicamente lavrável comprovada por sondagens, escavações subterrâneas e outras formas de amostragem em pontos pouco espaçados de modo a assegurar a sua continuidade e cujos dados geocientíficos (forma, dimensão, densidade, qualidade e teor) são conhecidos com confiabilidade ou, ALTERNATIVAMENTE, reserva calculada por métodos geoestatísticos onde o bloco estimado tenha dimensões pertinentes à escala de produção e proporcionalidade com os alcances variográficos e tenha no mínimo uma amostra na sua auréola de influência, o que eqüivale a determinar as relações de covariância amostra(s)/bloco, bloco/bloco e amostra(s)/amostra(s).

7) RESERVA PROVÁVEL: parte ou totalidade de um recurso indicado economicamente lavrável amostrada por sondagens, escavações subterrâneas e outras formas de amostragem em pontos com espaçamento insuficiente para assegurar a continuidade, porém suficiente para uma indicação razoável da mesma e cujos dados geocientíficos (forma, dimensão densidade, qualidade e teor) são conhecidos com razoável nível de confiabilidade, em condições tais que o minério provavelmente será confirmado, ou, ALTERNATIVAMENTE reserva calculada por métodos geoestatísticos onde o bloco estimado tenha dimensões pertinentes à escala de produção e proporcionalidade com os alcances variográficos e nenhuma amostra em sua auréola de influência, o que eqüivale a atribuir à variância de krigagem do bloco o valor da variância a priori mais o valor do covariograma do bloco. 